DOI: https://doi.org/10.21728/logeion.2016v3n1.p108-120

\title{
OS SENTIDOS DO TERMO VIRTUAL EM PIERRE LÉVY
}

\author{
Cleyton Leandro Galvão \\ Instituto Federal de Educação, Ciência e Tecnologia da Paraíba - IFPB \\ Mestre em Filosofia pela UFPE \\ Doutorando em Filosofia pelo programa de Doutorado Integrado UFPE-UFPB-UFRN. \\ Líder do Grupo de Pesquisa Mente, Tecnologia e Informação do IFPB. \\ cleyton.galvao@ifpb.edu.b
}

\begin{abstract}
Resumo
A intenção do trabalho é comparar os sentidos atribuídos ao virtual nas obras O que é o Virtual? (1995) e Cibercultura (1997) do filósofo francês Pierre Lévy. Para tal tarefa foi utilizada a metodologia da filosofia analítica da linguagem para distinguir os possíveis significados e sentidos que o termo virtual pode possuir. Na obra de 1995 o virtual é entendido então como potência, oposto ao atual, não ao real. Na obra de 1997 o virtual passa a ter ao menos três sentidos: o comum, o filosófico e o tecnológico. Numa escala de virtualidade, estes sentidos se desdobram em cinco posições, sendo o mais forte a Realidade Virtual e o mais fraco o do Senso Comum. A análise mostrou que o sentido de virtual atribuído em 1995 perde poder explicativo na obra de 1997 por desconsiderar o processo de digitalização como fator fundamental para a geração de elementos virtuais. A conclusão é que o conceito de 1995 é tão amplo que se torna estéril quando se trata de explicar as novas tecnologias da informação e comunicação, por isso ele é relegado a penúltimo lugar na escala dos sentidos do virtual na obra de 1997.
\end{abstract}

Palavras-chave: Virtual. Pierre Lévy. Digital. Cibercultura.

\section{THE MEANINGS OF VIRTUAL IN PIERRE LÉVY}

\begin{abstract}
This work-study compares the meanings attributed to the virtual in the books What is the Virtual? (1995) and Ciberculture (1997) by Pierre Lévy, French philosopher. To such a task we used the analytic philosophy of language methodology to distinguish the possible meanings and senses that the term virtual may have. In the book of 1995 the virtual is then understood as potential, as opposed to the current, not the real. In the book of 1997 the virtual is replaced by at least three senses: the common, the philosophical and the technological. In a virtual scale, these senses unfold in five positions, being the strongest Virtual Reality, and being the weaker the Common Sense. The analysis showed that the virtual meaning assigned in 1995 lost explanatory power in the work of 1997 by disregarding the scanning process as a key factor for generating virtual elements. The conclusion is that the concept of 1995 is so broad that it becomes sterile when it comes to explaining the new technologies of information and communication, so it is relegated to second bottom on the sense scale of virtual in the book of 1997.
\end{abstract}

Key-words: Virtual. Pierre Lévy, Digital. Cyberculture.

\section{Introdução}

Sabemos que na década de 1990 a internet ainda estava ganhando fôlego no uso doméstico, mesmo nos locais mais desenvolvidos da Europa e Estados Unidos. Havia a necessidade de compreender esse novo modo de se comunicar também da forma 
conceitual. No entanto, poucos pensadores se dispunham a isso. O grande interesse da população era se tornar um usuário, alguém conectado como o mundo num simples click. Apesar do clima de empolgação, muitos não viam com bons olhos essa invasão repentina aos lares e ambientes de trabalho.

O senso comum costumava, ou ainda costuma, tratar o virtual como uma quimera, algo semelhante a quando sonhamos. A realidade onírica, por mais realista que pareça, não tem o mesmo estatuto dos objetos que encontramos no dia-a-dia, tal como cadeiras, mesas e paredes. Tal realidade se dissolve ao abrir os olhos. Do contrário, o real é uma presença a qual podemos tocar, cheirar, ouvir, sentir. Assim, o virtual, ainda bastante atrelado à ideia de Realidade Virtual, foi tomado como uma espécie de ilusão tecnológica forjada pela capacidade crescente de cálculo do computador.

O filósofo e antropólogo francês Pierre Lévy, porém, insiste que a oposição entre real e virtual é enganosa. Estes modos de ser não correspondem a mundos opostos, mas são modos complementares de uma mesma entidade. No entanto, o virtual possui diversos sentidos que podem ser explorados filosoficamente.

O foco deste artigo, portanto, será exibir os vários sentidos atribuídos pelo filósofo Pierre Lévy ao conceito de virtual, comparando as obras $O$ que é o virtual? e Cibercultura.

\section{0 virtual em $O$ que é o virtual?}

Lançada originalmente em 1995, o livro $O$ que é o virtual? tem o intuito de resgatar o conceito de virtual das garras do senso comum, do qual se via prisioneiro há muito tempo. Era preciso alertar que tal conceito "tem somente uma pequena afinidade o com o falso, o imaginário ou o ilusório" (LÉVY, 2011, p. 12).

Resgatando a terminologia da escolástica medieval, o termo virtual vem de virtus, que significa força, potência. Assim, o virtual é algo que existe em potência e não em ato. Algo virtual tende a se atualizar através do tempo. Num exemplo clássico podemos dizer que a semente é uma árvore em potência. Nos termos de Lévy, ela é virtualmente uma árvore. Já a árvore é a semente em ato, depois de efetivada sua potencialidade. "Em termos rigorosamente filosóficos, o virtual não se opõe ao real mas ao atual: virtualidade e atualidade são apenas duas maneiras de ser diferentes" (LÉVY, 2011, p. 15). Desse modo, o par de oposição real-virtual é uma má concepção ou um preconceito intelectual que obscurece o entendimento do problema que nosso filósofo pretende combater. 
Ainda no seu empreendimento de resgatar a dignidade do virtual e localizá-lo devidamente no seu papel de fator de alteração cultural, Lévy toma de empréstimo a distinção entre o possível e o real, feita por Deleuze em Diferença e Repetição. O possível tem todas as características do real, mas de forma latente. Para que ocorra a passagem do possível para o real, basta efetivar sua existência. Um edifício possível tem sua distinção de um edifício real apenas no fato deste último existir e o outro não. Todas as suas características já estão lá: suas janelas, escadas, paredes, esperando somente a realização pelas mãos de seus construtores. "O possível é exatamente como o real: só lhe falta a existência [...] A diferença entre o possível e o real é, portanto, puramente lógica"1. (LÉVY, 2011, p. 16)

Reorganizando os modos de ser, podemos concluir que os pares corretos de oposição seriam possível-real e virtual-atual. O virtual é um nó de tendências que precisa de uma resolução inventiva, de uma criação. O virtual não é um "fantasma" do atual, tal como o possível seria do real. São necessários novos elementos para que o virtual passe para o atual. Mesmo a semente carregando a árvore em si mesma como potência não basta para sua realização em árvore, é preciso algo além. Cada "entidade carrega e produz suas virtualidades" (LÉVY, 2011,p. 16). Ao mesmo tempo, o virtual é parte essencial de uma entidade e da sua determinação.

Tendo definido o que é o virtual, temos que mudar a nossa atenção para o que Lévy (2011, p. 16) define como o seu polo oposto, o processo de geração do atual: "A atualização é criação, invenção de uma forma a partir de uma configuração dinâmica de forças e finalidades". Assim, no processo de atualização de uma entidade há mudanças irreversíveis que contarão para o surgimento do novo ente. "O real assemelha-se ao possível; em troca, o atual em nada se assemelha o virtual: responde-lhe" (LÉVY, 2011, p. 17).

Como uma mudança do efetivo para o potencial, a virtualização "desamarra" a entidade das coordenadas do espaço e do tempo. Deste modo, a virtualização de uma entidade é a passagem de uma resolução para o problema que lhe é inerente. Tomemos o exemplo dos perfis nas redes sociais. Cada perfil corresponde a identidade virtual do seu usuário. Em analogia a teoria de Lévy, a identidade pessoal, por ser o atual, é a

\footnotetext{
${ }^{1}$ Fazendo uma pequena correção na citação temos de observar que a distinção entre o possível e o real é ontológica, não lógica. A frase mais correta seria "a diferença entre o possível e o real é puramente ontológica", no entanto, não expressaria com concretude o que Lévy quis nos dizer sobre aquela oposição.
} 
resolução de um problema. Qual problema? O problema da identidade. Na virtualização da identidade pessoal surgem os perfis virtuais, como uma passagem da resposta para o problema, libertando a entidade das amarras do espaço-tempo:

\begin{abstract}
A virtualização não é uma desrealização (a transformação de uma entidade num conjunto de possíveis), mas uma mutação de identidade, um deslocamento do centro de gravidade ontológico do objeto considerado: em vez de se definir principalmente por sua atualidade (uma 'solução'), a entidade passa a encontrar sua consistência essencial num campo problemático. (LÉVY, 2011, p. 17-18)
\end{abstract}

Com tudo isso nós podemos perceber que um dos focos da análise do filósofo francês é a desterritorialização causada pelo virtual. É lógico que a desterritorialização não é total, pois o virtual sempre se atualiza em algum ponto do espaço-tempo. No entanto, essa desterritorialização continua "escapando a seus lugares comuns 'realistas': ubiquidade, simultaneidade, distribuição irradiada ou massivamente paralela". (LÉVY, 201, p. 21)

Um dos efeitos mais significativos do processo de virtualização é a alteração no modo como temos de lidar com o tempo. A noção de momento presente ganha pela primeira vez na história uma dimensão global. O presente está aqui e em todo lugar. O tempo é sincronizado, criando-se uma unidade temporal sem a necessidade da unidade de lugar, mesmo quando a duração da ação é descontínua. "A sincronização substitui a unidade de lugar, e a interconexão, a unidade de tempo". (LÉVY, 2011, p. 21)

Temos que levar em consideração que Lévy também questiona a natureza da informação quando quer explicar o que é o virtual. De forma retórica, ele induz que a primeira coisa que vem em mente para explicar as qualidades da informação é porque ela seria "imaterial". Isso suporia uma metafísica da substância que classifica os entes em materiais e imateriais. O problema é que os bens materiais são classificados pela sua forma, sua estrutura, suas propriedades, ou seja, pela sua dimensão "imaterial". Desta forma, somente as matérias-primas são puramente "materiais".

Ao contrário, não se pode separar a informação do seu suporte físico, sob pena de destruí-la. Se o suporte físico desaparece, também desaparece a informação. Para tentar escapar da dicotomia material-imaterial, Lévy aponta que a informação e o conhecimento são desterritorializados, não imateriais. Eles são da ordem do acontecimento ou do processo.

$\mathrm{Na}$ sequência da análise sobre a informação o filósofo francês declara expressamente que a informação é virtual. "Por que o consumo de uma informação não 
é destrutivo e sua posse não é exclusiva? Porque a informação é virtual?" (LÉVY, 2011,p. 58) Lévy elenca o fato de o virtual ser desterritorializado e ser uma passagem para a problemática para apoiar sua tese. "Quando utilizo uma informação, ou seja, quando a interpreto, ligo-a a outras informações para fazer sentido ou, quando me sirvo dela para tomar uma decisão, atualizo-a" (LÉVY, 2011, p. 58).

$\mathrm{Na}$ tentativa de distinguir o possível do virtual, Lévy levanta um exemplo complicado, talvez até contraditório com o que ele diz sobre sua concepção de pensar o processo da leitura como uma atualização do virtual (o texto):

Antes da sua leitura, a informação que corre no ciberespaço não é potencial, mas sim virtual, na medida em que pode assumir significações diferentes e imprevisíveis conforme se insira um determinado hiperdocumento ou em outro. Virtual porque aquilo que está em jogo não é a realização (cópia, impressão etc.), mas a atualização, a leitura, isto é, a significação que ela pode assumir em contexto, significação indissociável da participação deliberada de pelo menos um ser humano consciente. Virtual porque sua reprodução, sua cópia, não custam praticamente nada, salvo o custo geral de manutenção do ciberespaço. Virtual porque posso dar um documento sem perdê-lo e reempregar partes dele sem destruir o original. No ciberespaço, o documento torna-se tão impalpável e virtual quanto às informações e as próprias ideias. (LÉVY, 2011, p. 67)

É possível perceber nesta citação que ora o virtual é tratado como potencial, ora é tratado como correlato ao conceito de informação. Essa ambiguidade se arrasta pelo resto do livro $O$ que é o virtual?, deixando o conceito de virtual tão amplo que seu poder explicativo se perde quando são inseridas na análise novas formas de tecnologias. Esse problema será melhor visualizado na análise da obra Cibercultura.

Assim nesta polissemia este termo...

- é virtual porque é o potencial + sujeito.

- é virtual porque é significativo;

- é virtual porque é replicável;

Neste momento será preciso exibir o que Lévy considera o processo de formação do virtual para que fique claro porque sua posição filosófica não dará conta de explicar o sentido tecnológico do virtual.

Inspirado no modo clássico de educação, no trívio, que era composto pela Gramática, a Dialética e a Retórica, Lévy considera o processo de formação do virtual algo que leva em conta o processo de significar. Primeiro, há a gramatização, que é a 
separação em elementos não significantes que podem ser recombinados de maneiras infinitas. Após isso surge a dialética que consiste nas substituições que podem ser feitas entre as coisas. Por fim, surge a retórica como o elemento que propriamente cria o virtual, pois gera a liberdade, o vácuo, desterritorializando uma entidade:

Gramática, dialética e retórica sucedem-se apenas numa ordem lógica de exposição. Nos processos concretos de virtualização, são simultâneas, ou mesmo puxadas pela retórica. A gramática separa elementos e organiza sequências. A dialética faz funcionar substituições e correspondências. A retórica separa seus objetos de toda combinatória, de toda referência, para desdobrar o virtual como um mundo autônomo". (LÉVY, 2011, p. 94)

Em vez de levar em consideração o processo de digitalização para a formação do virtual, Lévy pensa a digitalização como um subprocesso da gramatização, pois separa elementos não significantes para recombiná-los de forma ilimitada. "A informática é a mais virtualizante das técnicas por ser também a mais gramaticalizante". (LÉVY, 2011, p. 88) Assim, depois de processados pela gramática, esses elementos seriam referidos ao "real", servindo em processo de substituições pela dialética: o andar pela roda, a mão pelo martelo, etc., para por fim, tais substituições serem separadas das referências no ato criativo que seria a retórica, verdadeira fundadora do virtual.

Fica evidente que nosso filósofo não toma a retórica como uma metáfora, mas como uma explicação do mundo. $\mathrm{O}$ que foi historicamente um processo de aprendizagem de habilidades linguísticas foi transformado, na obra de Lévy, num gerador de uma potência explicativa dos mais diversos aspectos humanos. Na sua visão, só a retórica seria capaz de elevar as entidades circunscritas no plano físico a outro modo de realidade. "O ato retórico, que diz respeito à essência do virtual, coloca questões, dispõe tensões e propõe finalidades; ele as põe em cena, as põe em jogo no processo vital. A invenção suprema é a de um problema, a abertura de um vazio no meio do real". (LÉVY, 2011, p. 94)

O processo descrito seria a explicação filosófica da formação do virtual. O intuito desta obra de 1995 foi distinguir o sentido comum do sentido filosófico de virtual. Com tal distinção Lévy acredita por explicar as mudanças culturais feitas a partir dos processos de virtualização, que seriam tão antigos quanto a própria humanidade. A explicação destes processos antropológicos não faz parte do nosso foco de pesquisa neste artigo.

\section{0 virtual em Cibercultura}


Diferente de 1995, Lévy aponta na obra de 1997, Cibercultura, o caminho para analisar o virtual mais profundamente naqueles sentidos antes mencionados. "A palavra "virtual" pode ser entendida em ao menos três sentidos: o primeiro, técnico, ligado à informática, um segundo corrente e um terceiro filosófico". (LÉVY, 2010, p. 49)

É interessante observar o paralelo que será traçado entre o sentido corrente, ou do senso comum, e o sentido filosófico traçado pelo nosso filósofo. Ele mantém a posição filosófica sobre o virtual da obra de 1995, radicalizando a tendência de pensar o virtual como potência que eclode numa atualização:

$\mathrm{Na}$ acepção filosófica, é virtual aquilo que existe apenas em potência e não em ato, o campo de forças e de problemas que tende a resolver-se em uma atualização. [...] No sentido filosófico, o virtual é obviamente uma dimensão muito importante da realidade. Mas no uso corrente, a palavra virtual é muitas vezes empregada para significar a irrealidade enquanto a "realidade" pressupõe uma efetivação material, uma presença tangível. (LÉVY, 2010, p. 49)

Levando isso em conta Pirre Lévy (2010, p. 49) pode definir o que é uma entidade virtual: "É virtual toda entidade 'desterritorializada', capaz de gerar diversas manifestações concretas em diferentes momentos e locais determinados, sem contudo estar ela mesma presa a um lugar ou tempo em particular". Ele usa as palavras como exemplos de entidades virtuais que se atualizam de tempos em tempos e lugares distintos. "Mas a palavra em si, [...] não está em lugar nenhum e não se encontra vinculada a nenhum momento em particular (ainda que ela não tenha existido desde sempre)" (LÉVY, 2010, p. 50).

Já é possível notar que o virtual foi definido primeiramente como algo em potência. Em seguida o virtual é definido como algo que pode se instanciar em lugares e tempos diferentes. Assim, no primeiro significado o virtual é potência e no segundo o virtual tem a mesma característica do conceito de informação, como veremos.

A parte mais significante do texto de 1997 para o nosso interesse é a escala dos sentidos que Lévy atribui ao virtual. Tal escala inicia do sentido mais forte para o mais fraco. O ponto-chave é o conceito de simulação e o controle do seu representante nesse ambiente virtual. Assim, quanto maior a sensação de imersão e simulação do mundo real, mais forte é o grau de virtualidade.

O primeiro nível e mais forte de virtualidade é o que se refere à Realidade Virtual, que "especifica um tipo particular de simulação interativa, na qual o explorador tem a sensação física de estar imerso na situação definida por um banco de dados". 
(LÉVY, 2010, p. 73) A introdução na realidade virtual pode ser feita através de óculos, capacetes, luvas e outros diversos elementos que ajudam o usuário a imergir sensorialmente num ambiente digital. Geralmente, quanto mais sentidos estimulados, maior será a simulação de realidade. É claro que o usuário não pode esquecer que está imerso numa realidade criada artificialmente. O computador precisa dar um feedback em tempo real das ações do usuário para que simule operações no mundo real. Os simuladores de combate são bons exemplos desse primeiro nível.

No segundo nível o virtual é assemelhado a um mapa da realidade, sem ter a necessidade de ser tridimensional. "As duas características distintivas do mundo virtual, em sentido mais amplo, são a imersão e a navegação por proximidade" (LÉVY, 2010, p. 75). Os participantes do mundo virtual são imersos através de um representante (avatar) que exibe a cada ato do usuário uma imagem do mundo virtual. O modo de interação é através da proximidade num espaço contínuo. "O explorador de um mundo virtual (não necessariamente "realista") deve poder controlar seu acesso a um imenso banco de dados de acordo com princípios e reflexos mentais análogos aos que o fazem controlar o acesso a seu ambiente físico imediato". (LÉVY, 2010, p. 75) Os videogames são bons exemplos desse segundo nível de virtualidade.

No terceiro nível o virtual é visto como significando informática. Este é o nível que leva em consideração a inserção de dados num computador para que seja considerado virtual, ou seja, é uma virtualidade resultante da digitalização da informação. "Diremos que uma imagem é virtual se sua origem for uma descrição digital em uma memória de computador" (LÉVY, 2010, p. 75). Lévy chega a traçar um paralelo entre a sua acepção filosófica de virtual e este terceiro modo de virtualidade para mostrar a diferença entre o potencial e o atual:

Se quiséssemos manter um paralelo com o sentido filosófico, diríamos que a imagem é virtual na memória do computador e atual na tela. A imagem é ainda mais virtual, por assim dizer, quando sua descrição digital não é um depósito estável na memória do computador, mas quando é calculada em tempo real por um programa a partir de um modelo e de um fluxo de dados de entrada. (LÉVY, 2010, p. 75-77)

Assim, já poderíamos afirmar que o conceito filosófico de Lévy está em penúltimo lugar na escada da virtualidade, pois ele tem pouca ou quase nenhuma sensação de imersão e interatividade, ganhando apenas para o sentido do senso comum que alega que o virtual é fictício e ilusório. 
Por fim, Lévy define mais precisamente o que ele pretende dizer com essa noção de virtualidade pelo digital. Lembrando que este grau é o mais fraco a partir da digitalização:

Essa virtualidade, resultante da digitalização, designa o processo de geração de automática ou de cálculo de uma grande quantidade de "textos", mensagens, imagens sonoras, visuais ou tácteis, de resultados de todos os tipos, em função de uma matriz inicial (programa, modelo) e de uma interação em processo. (LÉVY, 2010, p. 77)

Assim, temos na escala do virtual (cf. Quadro).

\section{Quadro - A escala do virtual do sentido mais fraco para o mais forte}

\begin{tabular}{|c|c|c|}
\hline & Definição & Exemplos \\
\hline $\begin{array}{l}\text { Virtual no } \\
\text { sentido comum }\end{array}$ & $\begin{array}{l}\text { Falso, ilusório, irreal, } \\
\text { imaginário, possível }\end{array}$ & \\
\hline $\begin{array}{l}\text { Virtual no } \\
\text { sentido } \\
\text { filosófico }\end{array}$ & $\begin{array}{l}\text { Existe em potência } \\
\text { e não em ato, existe } \\
\text { sem estar presente }\end{array}$ & $\begin{array}{l}\text { A árvore na semente (por oposição à } \\
\text { atualidade de uma árvore que tenha } \\
\text { crescido de fato) / uma palavra na língua } \\
\text { (por oposição à atualidade de uma } \\
\text { ocorrência de pronúncia ou } \\
\text { interpretação) }\end{array}$ \\
\hline $\begin{array}{l}\text { Mundo virtual } \\
\text { no sentido da } \\
\text { possibilidade } \\
\text { de cálculo } \\
\text { computacional }\end{array}$ & $\begin{array}{l}\text { Universo de } \\
\text { possíveis calculáveis } \\
\text { a partir de um } \\
\text { modelo digital e de } \\
\text { entradas fornecidas } \\
\text { por um usuário }\end{array}$ & $\begin{array}{l}\text { Conjunto das mensagens que podem ser } \\
\text { emitidas respectivamente por: } \\
\text { - programas para edição de texto, } \\
\text { desenho ou música; } \\
\text { - sistema de hipertexto; } \\
\text { - bancos de dados; } \\
\text { - sistemas especializados; } \\
\text { - simulações interativas etc. }\end{array}$ \\
\hline $\begin{array}{l}\text { Mundo virtual } \\
\text { no sentido do } \\
\text { dispositivo } \\
\text { informacional }\end{array}$ & $\begin{array}{l}\text { A mensagem é um } \\
\text { espaço de interação por } \\
\text { proximidade } \\
\text { dentro do qual o } \\
\text { explorador pode } \\
\text { controlar diretamente um } \\
\text { representante de si } \\
\text { mesmo }\end{array}$ & $\begin{array}{l}\text { - mapas dinâmicos de dados } \\
\text { apresentando a informação em função do } \\
\text { "ponto de vista", da posição ou do } \\
\text { histórico do explorador; } \\
\text { - RPG em rede; } \\
\text { - videogames; } \\
\text { - simuladores de voo; } \\
\text { - realidades virtuais etc. }\end{array}$ \\
\hline $\begin{array}{l}\text { Mundo virtual } \\
\text { no sentido } \\
\text { tecnoló-gico } \\
\text { estrito }\end{array}$ & $\begin{array}{l}\text { Ilusão de interação } \\
\text { sensório-motora com um } \\
\text { modelo } \\
\text { Computacional }\end{array}$ & $\begin{array}{l}\text { Uso de óculos estereoscópicos, } \\
\text { datagloves para } \\
\text { visitas a monumentos reconstituídos, } \\
\text { treinamentos em cirurgias etc. }\end{array}$ \\
\hline
\end{tabular}

Fonte: Lévy (2010, p. 76)

\section{Crítica ao conceito filosófico de virtual de Pierre Lévy}


À primeira vista, a acepção filosófica de Lévy aparenta ser capaz de lidar com todos os problemas que envolvem o termo 'virtual'. No entanto, observamos que há ao menos três grandes dificuldades na gerência na sua abordagem.

$\mathbf{1}^{\circ} \mathrm{O}$ problema da significação:

Em diversas passagens nas duas obras pesquisadas o virtual é exibido ora como correlato do conceito de potência, ora é exibido como apresentando algumas características que são geralmente atribuídas ao conceito de informação por diversos pensadores, inclusive pelo maior expoente da área na atualidade, o filósofo italiano Luciano Floridi.

O conceito de informação geralmente é definido como dados significativos e bem estruturados (cf. FLORIDI, 2005). Uma informação pode ser posta em papel, metal, madeira, pedra, o que for, mas não deixará de ser informação por causa do seu suporte físico. Essa capacidade, quando implementada em formato digital, amplia sua independência de um suporte físico específico, passando a ser além de desterritorializada e replicável, também sincronizada e interconectada a outras informações na rede.

$\mathrm{Na}$ nossa visão, Lévy inverte a ordem natural das coisas quando afirma que a informação é virtual: o virtual tem as características que tem porque é composto por informação, não o contrário. Na visão de Lévy é a informação que "pega emprestada" as características do virtual.

Assim, quando o virtual não dá conta de explicar um processo enquanto potência, então Lévy recorre a atributos informacionais para que ele se livre das coordenadas espaços-temporais e tente explicar formas mais contemporâneas de virtualidade.

\section{$2^{\circ} \mathrm{O}$ problema da digitalização:}

Lévy afirma que o virtual surge a partir do processo da gramática, dialética e retórica, o trívio. Ele não pensa esse processo como uma metáfora para explanar algo no qual ainda não possui conceito, tal como Platão fazia em seus diálogos com suas alegorias, mas como um processo real que ocorreria com diversos tipos de entidades, desde as palavras num texto até a inteligência artificial. Tudo seria, desse modo, restrito a significações.

No entanto, ele afirma que a virtualização não é algo hodierno, mas um movimento antigo, constituinte íntimo da própria humanidade. "Assim, a comunicação continua, com o digital, um movimento de virtualização iniciado há muito tempo pelas 
técnicas mais antigas, como a escrita, a gravação de som e imagem, o rádio, a televisão e o telefone". (LÉVY, 2010, p. 51)

Porém, pouco mais adiante no Cibercutura, Lévy (2010, p. 95) diz: "Insisto na codificação digital, pois ela condiciona o caráter plástico, fluido, calculável com precisão e tratável em tempo real, hipertextual, interativo e, resumindo, virtual da informação que é, parece-me, a marca distintiva do ciberespaço".

Levando esta citação em consideração poderíamos afirmar que as outras formas mais arcaicas de virtualização, como as palavras em papel, não seriam interativas, plásticas, fluidas, tratáveis em tempo real, etc. Assim, as características geralmente atribuídas ao virtual só teriam sentido com a digitalização da informação.

$3^{\circ} \mathrm{O}$ problema da fugacidade:

Talvez o grande problema com a noção de virtual concebida por Lévy é que ela se assemelha a dificuldade de apreender o momento presente. Quando tentamos "agarrar" o agora ele já deixou de ser presente e se tornou passado. Analogamente, o virtual de Lévy deixa de ser virtual assim que surge a presença humana, tornando-se ato. $O$ virtual não se mantém virtual. Esta é sua falha explanatória principal, pois fere todo o sentido tecnológico de virtual e se torna estéril em face às novas formas tecnológicas de comunicação.

Exemplo: digamos que alguém está utilizando um simulador de viagens espaciais como forma de treinamento para tripulantes. Durante a simulação haverá elementos na paisagem virtual que estarão em contato constante com os sentidos do usuário para gerar a sensação de imersão naquele ambiente. Na explicação de Lévy a cada interação do usuário com o simulador ocorrerá uma atualização do elemento virtual que está na base de dados digitais, tal como um texto seria virtual no papel e atual no momento da leitura, devido a significações atribuídas pelo leitor. "Ao interagir com o mundo virtual, os usuários o exploram e o atualizam simultaneamente." (LÉVY, 2010, p. 78). Ou seja, assim que o usuário entra em operação o virtual deixa de ser virtual e se torna atual. No entanto, isso parece contradizer qualquer experiência comum de um usuário num simulador. Os elementos simulados continuam virtuais durante a interação. Isto é garantido justamente pelo processo de digitalização da informação. É a interação com o virtual enquanto virtual que é o ponto principal da experiência simulada. Sem isso, o simulador não se diferenciaria do modo como o cinema foi concebido. 
Essa fugacidade do virtual na obra de Lévy é filha da concepção medieval que trata o virtual como uma espécie de não-ser. Diferentemente, dentro do panorama de Deleuze o virtual ganha contornos mais duradouros, segundo Craia (2009, p. 117):

[...] o virtual não é um momento primitivo, nem é parte de uma evolução que procura o atual para atingir sua completude; pelo contrario, o virtual coexiste e acompanha o atual no seu desdobrar-se, e não é eliminado no advento da atualidade.

Ao que parece, Lévy não consegue explicar como o virtual se mantém numa acepção tecnológica, quando um usuário é inserido no sistema, pois ele não leva em conta a digitalização como a mantenedora do virtual, mas como um subprocesso do trívio. Assim, cada participação do usuário é uma atualização na qual faz sumir o virtual ali presente.

\section{Conclusões acerca do virtual}

Num grande resumo dessa história podemos dizer que o sentido do virtual levantado por Pierre Lévy na primeira obra, $O$ que é o virtual?, é bastante enfraquecido quando se leva em consideração a digitalização da informação. $O$ digital permite a interatividade do usuário com os elementos informacionais, desde um simples acesso a um caixa eletrônico até simuladores de combate, inclusive passando pelas redes sociais. Abaixo disso está o sentido filosófico de Lévy, que ganha apenas para o do senso comum que trata o virtual como ilusório.

Vimos que o termo 'virtual' ora é tratado como potência ora tenta carregar as características da informação. Seria o virtual então um conceito híbrido? Num momento é potencial e num outro, informacional? Nosso entendimento é que não, ele não é. Lévy utiliza o conceito dessa forma polivalente com a intenção de lhe imbuir um grande poder explicativo. Assim, o virtual explicaria porque podemos ler um texto de Platão escrito a mais de dois mil anos atrás. "Conseguimos ler", diria Lévy, "porque o texto é virtual. Seus elementos são desterrritorializados". Além disso, explicaria como podemos interagir com um simulador de guerra. "Conseguimos porque os elementos digitais ali inseridos já são virtuais, computados numa grande velocidade de resposta às nossas ações", diria Lévy.

O problema é que o conceito filosófico de virtual de Lévy "diz tudo, mas não diz nada". Ou melhor, ele explica tudo, mas não convence. A negligência que ocorre na primeira obra em relação ao conceito de digitalização, substituindo-a pelo processo do 
trívio (gramaticalização, dialética e retórica), leva a explicação da formação do virtual à descrença. Se fosse uma metáfora, seria razoável. Mas não é. O que ocorre é que o virtual sem o digital não é nada. O digital é o demiurgo, aquilo que plasma os processos eletrônicos em elementos interativos e vice-versa. Sem o digital o que Lévy chama de virtual é apenas informação inserida em algum suporte físico, seja papel, em rochas, madeira, o que for.

No entanto, as intuições de Lévy são dignas de atenção. Sua insistência em tratar o Virtual como Real, ontologicamente, é válida não somente pelo fato de o virtual produzir efeitos no mundo, mas como sendo um fator condicionante de mudanças sociais. Arriscaria dizer que o virtual hoje 'pesa' mais que o atual. O mundo está sendo regido pela sua lógica, a lógica do Tempo-real e da ubiquidade.

É muito mais fácil, prático e significativo explicar o virtual pelo digital. $\mathrm{O}$ virtual é o digital em interação com o usuário. A tentativa que Lévy faz em salvar o virtual via uma semântica acaba resultando numa filosofia da informação ruim, pois negligencia justamente o que quer explicar: o fato de o virtual possuir as características de ser desterritorializado, sincronizado, replicável e correlacionado. Também resulta numa ontologia confusa que não consegue distinguir claramente os conceitos de real e atual, pois não há marca distintiva entre eles sem levar em conta os conceitos de possível e virtual.

Ele "virtualiza" a informação, confundido os conceitos e perdendo poder explanatório. Seu virtual é tudo e, por isso, é nada.

\section{Referências}

CRAIA, Eladio. O virtual: destino da ontologia de Gilles Deleuze. Revista de Filosofia Aurora, Curitiba, v. 21, n. 28, p. 107-123, jan./jun. 2009.

LÉVY, Pierre. Cibercultura. 3 ed. Tradução de Carlos Irineu da Costa São Paulo: Editora 34, 2010.

LÉVY, Pierre. O que é o virtual? 2 ed. Tradução de Paulo Neves. São Paulo: Editora 34, 2011.

FLORIDI, Luciano. Is semantic information meaningful Data? Philosophy and Phenomenological Research, v. 70, n. 2, p. 351-370, 2005. 